\title{
DIRECT MEASUREMENTS OF YOUNG'S MODULUS AND TENSILE STRENGTH OF POLYSILICON
}

\author{
William N. Sharpe, Jr., Bin Yuan, and Ranji Vaidyanathan \\ Department of Mechanical Engineering, \\ Johns Hopkins University \\ Baltimore, Maryland 21218-2686
}

Richard. L. Edwards

Applied Physics Laboratory

Johns Hopkins University

Laurel, MD 20723-6099

\begin{abstract}
Techniques and procedures have been developed for testing thin films under uniaxial tensile loading. Polysilicon specimens $3.5 \mu \mathrm{m}$ thick are deposited on silicon wafers in the shape of a tensile specimen with a supporting frame. The specimen is released by etching away the silicon wafer under the tensile section only. The frame containing the specimen is mounted in a loading mechanism consisting of a linear air bearing, a load cell, and a piezoelectric translator. The supporting frame is then cut and the specimen loaded in uniaxial tension. Strain is measured by laser-based interferometry from two thin gold lines deposited on the specimen.

This approach enables measurement of Young's modulus in a direct manner consistent with its definition. Results are presented from two different manufacturing (MUMPS) runs at the Microelectronic Center of North Carolina (MCNC). the overall average of Young's modulus is $168 \mathrm{GPa} \pm 7.6 \mathrm{GPa}$, and the tensile strength is $1.25 \mathrm{GPa} \pm 0.16 \mathrm{GPa}$.
\end{abstract}

\section{INTRODUCTION}

Most measurements of the elastic and strength properties of polysilicon and other thin films have been by indirect methods, i.e. the measured quantity (usually deflection) is related to the applied load or pressure by an equation that includes the material property of interest. The standardized definition of Young's Modulus is given in the American Society for Testing and Materials (ASTM) standard E-111 which states, "The test specimen is loaded uniaxially and load and strain are measured, either incrementally or continuously."'[1]. Further, ASTM E-111 requires that strain be measured directly on the specimen with suitable extensometers.

There have been measurements of mechanical properties of polysilicon that loaded the specimens uniaxially, but all recorded the relative displacement between the ends of the specimens and used it to compute the strain $[2,3,4]$. The measurements reported here are the first that fulfill the requirements of ASTM.

\section{SPECIMEN PREPARATION AND HANDLING}

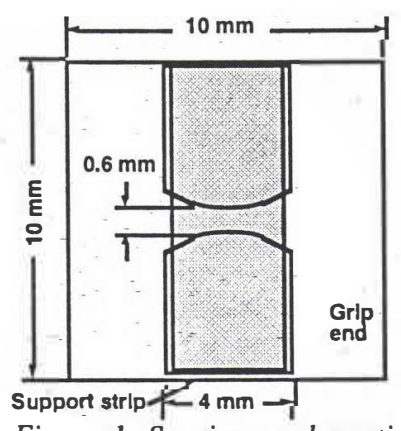

Figure 1. Specimen schematic.
The material tested is phosphorus doped, LPCVD polysilicon deposited at MCNC. As such, it is representative of the material commonly used to form structural elements for surface micromachined MEMS devices. The specimen is deposited on a silicon wafer in the shape shown in Figure 1 with the tensile portion in the middle and two support strips on each side. The silicon die is $1 \mathrm{~cm}$ square and the specimen is $3.5 \mu \mathrm{m}$ thick and $0.6 \mathrm{~mm}$ wide at its narrowest point. The wafer material beneath the tensile section and in the shaded area shown in Figure 1 is removed from the back of the die by anisotropic etching leaving the tensile polysilicon portion suspended between two grip ends that are connected by the support strips.

Figure 2 is a SEM photograph showing the specimen from an oblique view; there one can see the silicon wafer in the foreground and the polysilicon layer on top. The tensile specimen is stretched across the center of the photograph between the two grips.

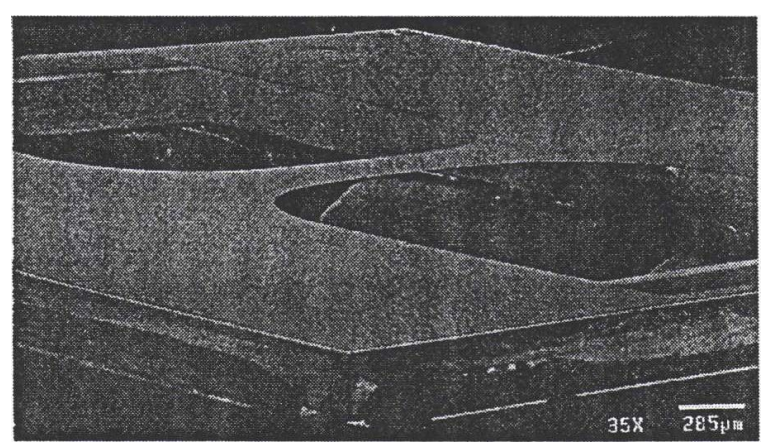

Figure 2. SEM photo after the substrate is etched away. The tensile specimen is in the middle of the picture.

\section{STRAIN MEASUREMENT}

Strain is measured with the Interferometric Strain Displacement Gage (ISDG) which is an optical technique for measuring the relative displacement between two reflective gage markers. For the polysilicon specimens, these two markers are gold lines that are deposited on the specimen during manufacture. Figure 3 is a schematic that illustrates the principle of the ISDG. The two gold lines are $0.5 \mu \mathrm{m}$ high, 20 $\mu \mathrm{m}$ wide, $200 \mu \mathrm{m}$ long and $300 \mu \mathrm{m}$ apart.

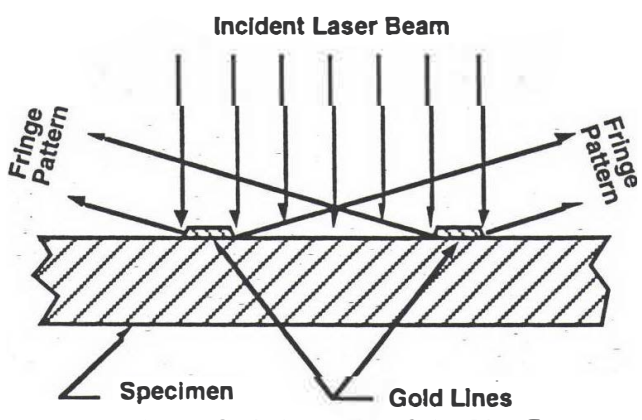

Figure 3. Schematic of the ISDG 
When the gold lines are illuminated with a laser, the diffracted reflections from each edge of a line overlap and interfere to produce fringes. As the gage markers move relative to each other, the fringe patterns also move; their motion can be measured with photosensors and related to the relative displacement change generated by -strain (or displacement if the lines are across a crack). Rigid-body motion will also cause the fringes to move, so it-is necessary to average the movement of the two fringe patterns.

The principal attributes of the ISDG as used in these measurements is its non-contacting, non-reinforcing nature. The resolution is approximately 10 microstrain and the relative uncertainty is $\pm 3 \%$. The ISDG is an established technique; a presentation of the optical principles as well as details of typical measurement systems is given in a NASA report [5].

\section{TEST SYSTEM}

The specimen, mounted in its carrier frame, is placed across a set of grips and the grip ends glued in place. One grip is fixed and the other one is attached to a linear air bearing whose slide connects to a load cell mounted on a piezoelectric actuator. This eliminates the friction in the loading mechanism and permits accurate measurements of the forces on the specimen. The piezoelectric translator has a range of $180 \mu \mathrm{m}$ with a resolution of $0.09 \mu \mathrm{m}$ and is controlled by the system microcomputer, i.e. the tests are conducted under displacement control. The load cell has a range of $1 \mathrm{lb}$ with a resolution of $0.001 \mathrm{lb}$. The two support strips are then cut and the specimen is pulled to failure while recording the load and strain.

A schematic of the entire test system, absent the microcomputer that controls the loading and records the strain, is shown in Figure 4.

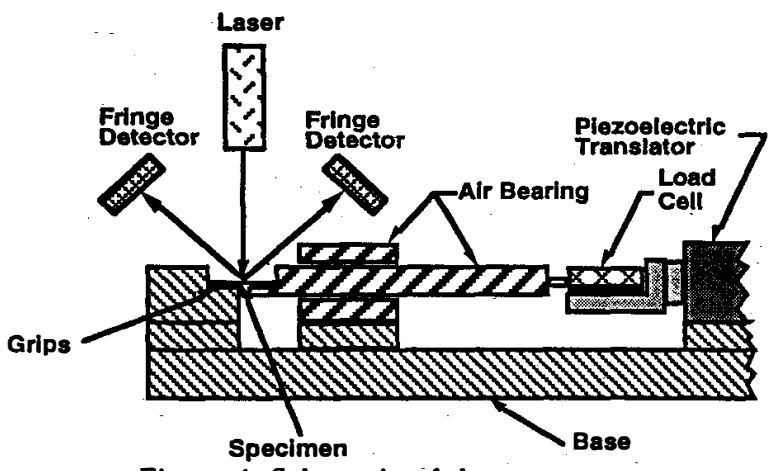

Figure 4. Schematic of the test system.

\section{RESULTS}

Figure 5 is a representative polysilicon stress-strain curve. The relative uncertainty in the stress arises primarily from the cross-section measurement and is $\pm 1 \%$.

We have conducted 10 tests of specimens from the MUMPS 6 run and 9 on specimens from MUMPS 8.

$\begin{array}{lcccc}\text { Young's } & \begin{array}{c}\text { Standard } \\ \text { Modulus } \\ \text { GPa }\end{array} & \begin{array}{c}\text { Teviation } \\ \text { GPa }\end{array} & \begin{array}{c}\text { Strength } \\ \text { GPa }\end{array} & \begin{array}{c}\text { Standard } \\ \text { Deviation } \\ \text { GPa }\end{array} \\ \text { MUMPS 6 } & 163 & 4.8 & 1.23 & 0.20 \\ \text { MUMPS 8 } & 173 & 6.9 & 1.27 & 0.11 \\ \text { All Data } & 168 & 7.6 & 1.25 & 0.16\end{array}$

The Young's modulus compares well with other modulus measurements $[3,6]$, while the mean tensile strength is lower than in polysilicon fibers [3], which may be due to either a size effect or the differences in the manufacturing process.

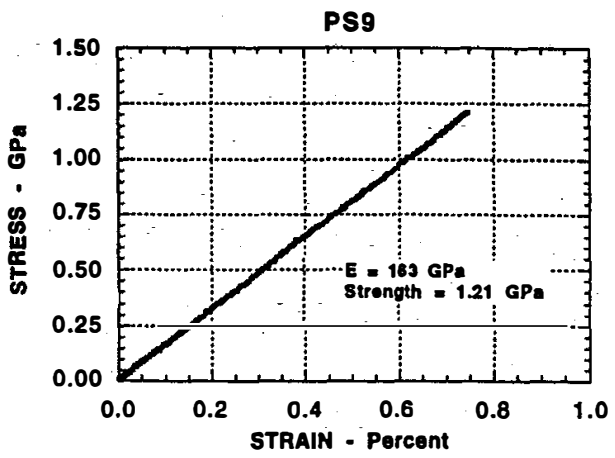

Figure 5. Representative stress-strain curve for polysilicon.

A statistical ' $\mathrm{t}$ ' test applied to the two groups of data shows that there is a statistically significant difference in the modulus values between the two manufacturing runs, but not in the strength values.

\section{CONCLUSIONS}

The reproducibility of the modulus -speaks well for the test technique. The strength has a wider scatter, but this is to be expected in a brittle material. The measurements show that the manufacturing process is controlled well.

This test system is able to solve the three main problems in conducting microsample tensile tests of extremely thin and fragile MEMS materials - ease of specimen preparation and handling, friction in the loading mechanism and accurate strain measurement.

The test techniques and procedures are now fully developed and can be used for important studies of new and existing materials that are used in MEMS.

\section{ACKNOWLEDGMENTS}

This research was sponsored by the National Science Foundation Grant MSS-9313302 and by the Physical Science Directorate of the Army Research Laboratory. The authors gratefully acknowledge the technical support of colleagues at MCNC.

\section{REFERENCES}

1. "Standard Test Method for Young's Modulus, Tangent Modulus, and Chord Modulus", E-111, 1990 Annual Book of ASTM Standards, American Society for Testing and Materials, Philadelphia (1990), pp. 276-281.

2. J. A. Schweitz, "Mechanical Characterization of Thin Films by Micromechanical Techniques," MRS Bulletin, 17, pp. 34-45 (1992).

3. J. Koskinen, J. E. Steinwall, R., Soave, and H. H. Johnson, "Microtensile Testing of Free-Standing Polysilicon Fibers of Various Grain Sizes", Journal of Micromechanics and Microengineering, 35, pp. 13-17 (1993).

4. D.T. Read and J.W. Dally, "A New Method for Measuring the Strength and Ductility of Thin Films," Journal of Materials Research , 8, No. 7, pp. $1542-1549$ (1993).

5. W. N. Sharpe, Jr., "An Interferometric Strain/Displacement Measurement System", NASA Technical Memorandum 101638, (1989).

6. M.-Biebl, T. Scheiter, C. Hierold, H. V. Philipsborn, H. Klose, "Micromechanics Compatible with an $0.8 \mathrm{~mm}$ CMOS Process," Sensors and Actuators A, 46-47, pp. 593-597 (1995). 